\title{
The Promise of Aggregation-Induced Emission Luminogens for Detecting COVID-19
}

\begin{abstract}
Zongwei Liu ${ }^{1}$, Ting Meng ${ }^{2}$, Xiaofang Tang ${ }^{3}$, Ran Tian ${ }^{4 *}$ and Weijiang Guan ${ }^{3 *}$
${ }^{1}$ Department of Respiratory Medicine, Lianyungang Hospital of Traditional Chinese Medicine, Affiliated Hospital of Nanjing University of Chinese Medicine, Lianyungang, China, ${ }^{2}$ The First Clinical Medical College, Nanjing University of Chinese Medicine, Nanjing, China, ${ }^{3}$ State Key Laboratory of Chemical Resource Engineering, College of Chemistry, Beijing University of Chemical Technology, Beijing, China, ${ }^{4}$ Public Laboratory, Tianjin Medical University Cancer Institute and Hospital, National Clinical Research Center for Cancer, Key Laboratory of Cancer Prevention and Therapy, Tianjin's Clinical Research Center for Cancer, Tianjin, China
\end{abstract}

The long-term pandemic of coronavirus disease 2019 (COVID-19) requires sensitive and accurate diagnostic assays to detect severe acute respiratory syndrome coronavirus 2 (SARS-CoV-2) virus and SARS-CoV-2 antibodies in infected individuals. Currently, RNA of SARS-CoV-2 virus is mainly detected by reverse transcription-polymerase chain reaction (RT-PCR)-based nucleic acid assays, while SARS-CoV-2 antigen and antibody are identified by immunological assays. Both nucleic acid assays and immunological assays rely on the luminescence signals of specific luminescence probes for qualitative and quantitative detection. The exploration of novel luminescence probes will play a crucial role in improving the detection sensitivity of the assays. As innate probes, aggregation-induced emission (AIE) luminogens (AlEgens) exhibit negligible luminescence in the free state but enhanced luminescence in the aggregated or restricted states. Moreover, AlEgen-based nanoparticles (AlE dots) offer efficient luminescence, good biocompatibility and water solubility, and superior photostability. Both AlEgens and AlE dots have been widely used for high-performance detection of biomolecules and small molecules, chemical/biological imaging, and medical therapeutics. In this review, the availability of AIEgens and AIE dots in nucleic acid assays and immunological assays are enumerated and discussed. By building a bridge between AIE materials and COVID-19, we hope to inspire researchers to use AIE materials as a powerful weapon against COVID-19.

Keywords: COVID-19, diagnosis, aggregation-induced emission, immunoassay, nucleic acid

\section{INTRODUCTION}

Coronavirus disease 2019 (COVID-19), caused by severe acute respiratory syndrome coronavirus 2 (SARS-CoV-2) virus, has spread over 216 countries/regions and resulted in more than 84 million infected cases and nearly 1.8 million deaths (1). SARS-CoV-2 is an RNA virus and has five open reading frames (ORFs) to encode the hemagglutinin esterase dimer protein (HE), the spike protein $(\mathrm{S})$, the envelope protein $(\mathrm{E})$, the glycosylated membrane protein $(\mathrm{M})$, and the nucleocapsid protein $(\mathrm{N})$, respectively $(2,3)$. The pathogenesis of SARS-CoV-2 infection contains two courses: virus entry cell and virus replicates. During the cellular entry of the virus, the $S$ protein plays a key role through host recognition and is closely associated with the human receptor 
angiotensin-converting enzyme 2 (ACE2), which is highly expressed in the lung, stomach, small intestine, colon, kidney, and lymph nodes (4-6). The human immune system responds to viral infection via the innate and adaptive immune systems, gradually producing antibodies against SARS-CoV-2 (7). Despite the use of multiple therapies over nearly a year, there are still no effective treatments for SARS-CoV-2 infection. Thus, the most effective and economical strategy is to identify infected individuals and prevent healthy individuals from coming into contact with infected individuals.

Current detection methods can be divided into two categories: nucleic acid assays and immunological assays (8-12). Nucleic acid assays directly detect the presence of SARS-CoV-2 virus in the upper respiratory tract during the first days of infection. Among nucleic acid assays, reverse transcription-polymerase chain reaction (RT-PCR)-based assays are currently considered the gold standard and are generally composed of six steps: (1) collection of respiratory samples using swabs, (2) inactivation of SARS-CoV-2 using lysis buffer, (3) purification of the SARS-CoV-2 RNA, (4) conversion of the purified RNA to complementary DNA (cDNA) using reverse transcriptase, (5) amplification of the specific regions of cDNA using primers, and (6) detection of the amplified cDNA using luminescence probes (11). The design of primers and probes targeting different regions of the SARS-CoV-2 genome can significantly affect the detection sensitivity, as low-performance nucleic acid amplifications and probes may generate false negatives. Moreover, nucleic acid assays require specialized instruments and complicated operations and are of little help in identifying past infections and monitoring infection status and immune progress (13). On the other hand, immunological assays with simpler design enable convenient and rapid detection of SARSCoV-2 antigen, immunoglobulin $\mathrm{M}$ (IgM) and immunoglobulin G (IgG) antibodies in the serum of infected individuals (8). IgM and IgG are generally produced after 5-10 d upon SARS$\mathrm{CoV}-2$ infection and last for several weeks (8). Immunological assays rely on the formation of immune complexes between the antibody and antigen. In the presence of appropriate substrates, luminescence probes labeled on the antibody or antigen can be activated to produce a given luminescence that is capable of both qualitative observation under a UV lamp and qualitative analysis on a spectrophotometer. Obviously, the detection sensitivity of nucleic acid assays and immunological assays is closely related to the performance of the luminescence probes. However, conventional luminescence probes inevitably encounter the aggregation-caused quenching (ACQ) problem at high target concentrations, greatly limiting their performance.

Aggregation-induced emission (AIE), first proposed by Tang in 2001, is a diametrically opposite phenomenon to ACQ (14). The luminogen with AIE characteristics is named AIEgen, which has no/low luminescence in the molecularly dispersed state but enhanced luminescence in the aggregated state (14-18). Further mechanistic studies indicate that strong luminescence can be also achieved by restricting the intramolecular motions (RIM) of the AIEgens in the molecularly dispersed state (16-18). After 20 years of outstanding development, a great family of AIEgens has been established, ranging from twisted conjugated AIEgens to planar conjugated AIEgens and irregular non-conjugated AIEgens (1421). Moreover, AIEgen-based nanoparticles (AIE dots) have been well-developed to obtain highly efficient luminescence (22-25). Both AIEgens and AIE dots are widely used for the highperformance detection of small molecules and biomolecules, chemical/biological imaging, and medical therapeutics (15, 22 33). Undoubtedly, some of them can be used for nucleic acid assays and immunological assays. Therefore, this review aims to bridge the gap between AIE materials and COVID-19 detection and proposes AIE materials as potential diagnostic weapons against COVID-19. Possible candidates for nucleic acid assays and immunological assays are summarized. This knowledge may contribute to the development of advanced diagnostic kits that are effective for more sensitive assays.

\section{AIEgens EXHIBIT GREAT POTENTIAL FOR NUCLEIC ACID ASSAYS}

Since the number of viruses reach the maximum in the first few days of infection, nucleic acid assays can provide the earliest information to determine the presence or absence of the SARS-CoV-2 virus (9). Although the protocols and advances of nucleic acid assays have been reviewed (8-12), little attention is paid to the design of luminescence probes for highly sensitive detection of the amplified cDNA. Typically, commercial double-stranded DNA (dsDNA) binding dyes (e.g., SYBR Green) show low luminescence in the free state but enhanced luminescence upon insertion into the dsDNA sequence (9). Their luminescence intensity increases quantitatively with the exponential amplification of cDNA. However, the short Stokes shift $(<30 \mathrm{~nm})$ allows a large overlap between the absorption and emission spectra, which leads to self-absorption or inner-filter effects, thus reducing the signal-to-noise ratio and the detection sensitivity (30). There is no doubt that further innovations in producing more efficient luminescence signals and outputs could significantly improve the detection sensitivity. Therefore, this section focuses on the great potential of using AIEgen-based DNA probes to improve the sensitivity of current nucleic acid assays.

Similar to SYBR Green, AIEgen-based DNA probes show low luminescence in the free state but enhanced luminescence upon binding to dsDNA, which is caused by RIM (32-51). AIEgen-based DNA probes (Figure 1) consist of two parts: AIE-active groups for producing light-up signals and targeting groups for binding to DNA (34-53). The AIE-active groups have a larger Stokes shift $(>100 \mathrm{~nm})$ compared to SYBR Green, which prevents the reabsorption or inner-filter effects as well as aggregation-caused quenching, thereby improving sensitivity. The effect of AIEgen structures on DNA detection has been systematically revealed by studying the number of binding groups, the length of hydrophobic linking groups and the molecular conformation. Taking the AIEgens 1, 3, and 5 as examples $(39,42)$, their cationic amino-groups can endow them with good water solubility to avoid the aggregation and fluorescence of the AIE-active tetraphenylethene (TPE) groups. Meanwhile, these amino-modified AIEgens can firmly bind 


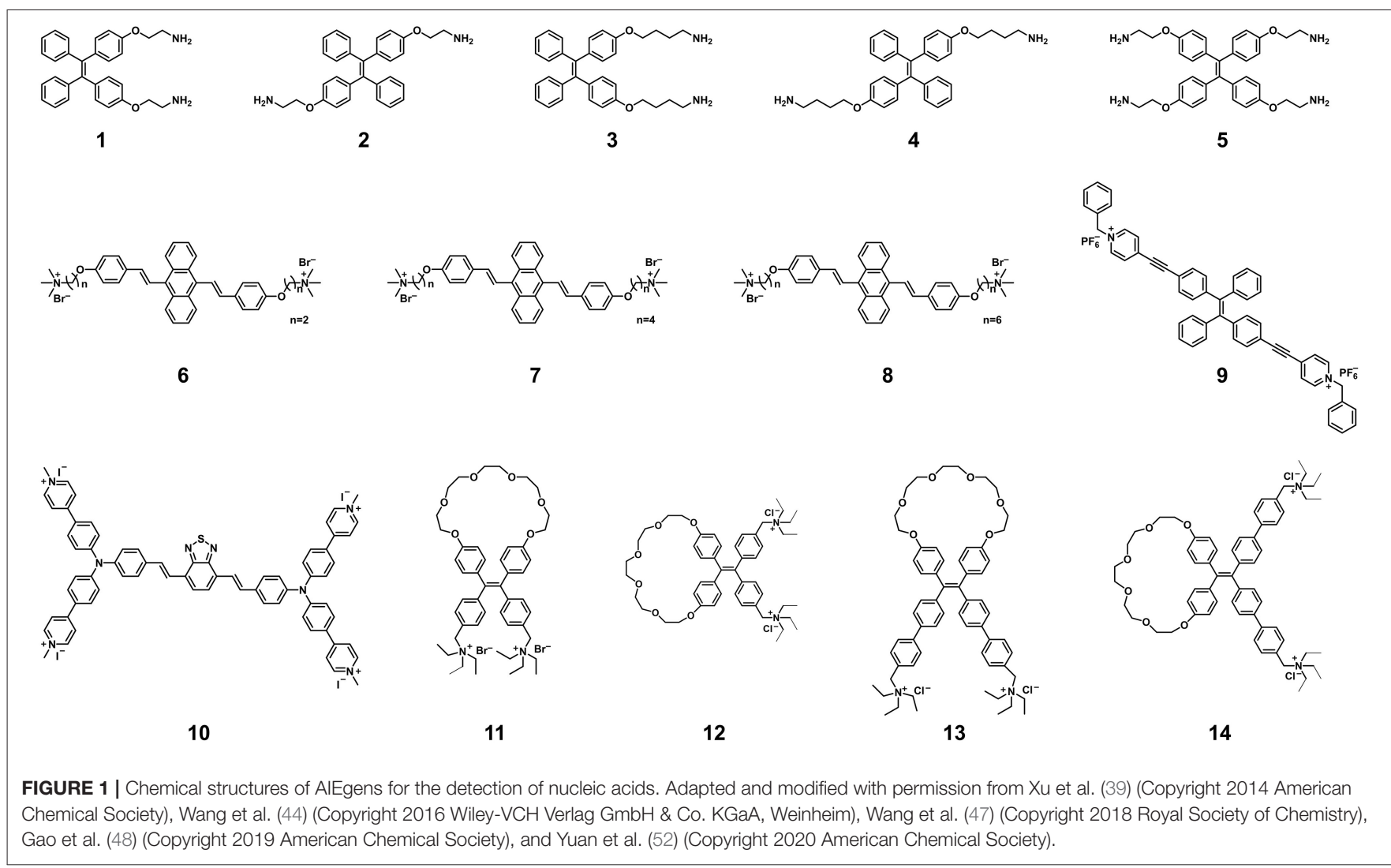

negatively charged dsDNA through electrostatic interactions and hydrogen bonds, resulting in TPE aggregation to display strong fluorescence. The detection limit of AIEgen $\mathbf{1}$ and AIEgen 3 with two amino-groups were much lower than that of AIEgen 5 with four amino-groups, indicating that the extra two aminogroups cannot make AIEgens bind dsDNA more firmly but reduce the aggregation of TPE groups. On the other hand, AIEgen 3 with longer hydrophobic linking groups showed higher sensitivity than AIEgen $\mathbf{1}$ with shorter hydrophobic linking groups. This result demonstrated that stronger hydrophobic interactions between AIEgens can facilitate the aggregation of TPE groups, leading to the enhanced fluorescence and higher sensitivity. Based on the revealed relationship between the AIEgen structures and detection sensitivity, AIEgens 11-14 with restriction of double-bond rotation were developed to further improve the sensitivity of sensing DNA (52). In addition, the conformational change of AIEgen 10 results in a two-color fluorescent signal from red to green, enabling selective and sensitive determination of dsDNA (48). When bound to anionic macromolecules, AIEgen $\mathbf{1 0}$ emits a bright red fluorescence at about $640 \mathrm{~nm}$. Interestingly, dsDNA can wrap around AIEgen 10 and change its molecular conformation, resulting in a change in conjugation and bright green fluorescence of about $537 \mathrm{~nm}$. From these published studies, it is understood that AIEgens with two binding sites, proper hydrophobicity and variable conformation enable sensitive detection of dsDNA. To facilitate the utilization of AIEgen-based DNA probes, their detection limits for dsDNA are summarized in Table 1. It is clear that AIEgen-based DNA probes are like a vast treasure trove, and some of them can serve as reliable and sensitive fluorescence probes that can be quickly adapted to SARS-CoV-2 PCR assays after proper calibration. At the same time, more efforts are needed to develop new AIEgens for other nucleic acid-based SARS-CoV-2 assays.

\section{AIEgens EXHIBIT GREAT POTENTIAL FOR IMMUNOLOGICAL ASSAYS}

Theoretically, if the luminescence signals can increase with the concentrations of luminescent labels without the ACQ problem, the detection sensitivity for immunological assays will be continuously improved. This is exactly the strength of AIE, therefore, this section focuses on the great potential of using AIEgens and AIE dots to improve the sensitivity of current immunoassays, such as enzyme-linked immunosorbent assays (ELISA) and lateral flow immunoassays.

ELISA is typically performed on the plate wells coated with the SARS-CoV-2 viral protein. The SARS-CoV-2 antibody (if present) can specifically bind the SARS-CoV-2 viral protein to form antibody-protein complex, which can be detected by an additional tracer antibody. This assay is very fast and results can be obtained within 1-5h. Various AIEgens with switchable luminescence have been successfully used in ELISA (54-58), and can be good candidates for constructing ELISA to detect 
TABLE 1 | Summary of detection limits for dsDNA.

\begin{tabular}{|c|c|c|c|}
\hline AlEgens & Target analyte & LOD & References \\
\hline \multirow[t]{3}{*}{1} & 75-300 bp & $4 \mathrm{ng} / \mathrm{band}$ & (39) \\
\hline & $50 \mathrm{bp}$ & $10.5 \mathrm{ng} / \mathrm{band}$ & \\
\hline & $35 \mathrm{bp}$ & $15 \mathrm{ng} / \mathrm{band}$ & \\
\hline 5 & $50 \mathrm{bp}$ & $>42$ ng/band & \\
\hline \multirow[t]{7}{*}{3} & $75-300 \mathrm{bp}$ & $1 \mathrm{ng} / \mathrm{band}$ & \\
\hline & $50 \mathrm{bp}$ & $<3.5$ ng/band & \\
\hline & $35 \mathrm{bp}$ & $5 \mathrm{ng} / \mathrm{band}$ & \\
\hline & $25 \mathrm{bp}$ & $7.5 \mathrm{ng} / \mathrm{band}$ & \\
\hline & $20 \mathrm{bp}$ & $8 \mathrm{ng} / \mathrm{band}$ & \\
\hline & $15 \mathrm{bp}$ & $19 \mathrm{ng} / \mathrm{band}$ & \\
\hline & $10 \mathrm{bp}$ & $<24$ ng/band & \\
\hline \multirow[t]{7}{*}{1} & $75-300 \mathrm{bp}$ & $1 \mathrm{ng} / \mathrm{band}$ & (42) \\
\hline & $50 \mathrm{bp}$ & $<3.5 \mathrm{ng} / \mathrm{band}$ & \\
\hline & $35 \mathrm{bp}$ & $2.5 \mathrm{ng} / \mathrm{band}$ & \\
\hline & $25 \mathrm{bp}$ & $5 \mathrm{ng} / \mathrm{band}$ & \\
\hline & $20 \mathrm{bp}$ & $5.3 \mathrm{ng} / \mathrm{band}$ & \\
\hline & $15 \mathrm{bp}$ & $9.5 \mathrm{ng} / \mathrm{band}$ & \\
\hline & $10 \mathrm{bp}$ & $12 \mathrm{ng} / \mathrm{band}$ & \\
\hline $6+\mathrm{GO} 1$ & $\mathrm{~T} 1$ & $0.17 \times 10^{-9} \mathrm{M}$ & (44) \\
\hline $6+\mathrm{GO} 2$ & & $11.8 \times 10^{-9} \mathrm{M}$ & \\
\hline $6+\mathrm{GO} 3$ & & $15.5 \times 10^{-9} \mathrm{M}$ & \\
\hline $7+\mathrm{GO} 1$ & & $2.7 \times 10^{-9} \mathrm{M}$ & \\
\hline $7+\mathrm{GO} 2$ & & $22.9 \times 10^{-9} \mathrm{M}$ & \\
\hline $7+\mathrm{GO} 3$ & & $26.1 \times 10^{-9} \mathrm{M}$ & \\
\hline $8+\mathrm{GO} 1$ & & $2.1 \times 10^{-9} \mathrm{M}$ & \\
\hline $8+\mathrm{GO} 2$ & & $24.1 \times 10^{-9} \mathrm{M}$ & \\
\hline $8+\mathrm{GO} 3$ & & $22.4 \times 10^{-9} \mathrm{M}$ & \\
\hline 9 & DNA (cas: 9007-49-2) & $0.02 \mu \mathrm{g} / \mathrm{mL}$ & $(47)$ \\
\hline \multirow[t]{2}{*}{10} & ct DNA & $1.75 \mathrm{ng} / \mathrm{mL}$ & $(48)$ \\
\hline & WT HIV DNA & $7.2 \times 10^{-11} \mathrm{M}$ & \\
\hline 11 & FS-DNA & $123 \mathrm{pM}$ & (52) \\
\hline 13 & & $74 \mathrm{pM}$ & \\
\hline 12 & & $496 \mathrm{pM}$ & \\
\hline 14 & & $235 \mathrm{pM}$ & \\
\hline 11 & ct DNA & $7.3 \mathrm{ng} / \mathrm{mL}$ & \\
\hline 13 & & $1.6 \mathrm{ng} / \mathrm{mL}$ & \\
\hline 12 & & $22 \mathrm{ng} / \mathrm{mL}$ & \\
\hline 14 & & $2.1 \mathrm{ng} / \mathrm{mL}$ & \\
\hline
\end{tabular}

SARS-CoV-2 infection. For example, a dual-modality readout immunoassay platform was developed using AIEgen-based signal unit consisting of streptavidin-alkaline phosphatase (SA-ALP), TPE-APP with enzyme cleavage sites, and gold nanoparticles (56). When the immunocapture unit composed of magnetic beads, anti-VP1 monoclonal antibodies (mAb-VP1), rabbit polyclonal antibodies ( $\mathrm{P}-\mathrm{Ab}$ ) and biotinylated antibodies (Biotin$\mathrm{Ab}$ ) captures the target EV71 virus, SA-ALP will promote the hydrolysis of the water-soluble TPE-APP to produce the waterinsoluble TPE-DMA, resulting in the aggregation of TPE-DMA in water and the emission of bright fluorescence (Figures 2A,B). The fluorescence turn-on mode gives the immunoassay platform a lower detection limit, as low as 1.4 copies/ $\mu \mathrm{L}$ (56). At the same time, the hydrolysis of TPE-APP can mediate the reduction of silver ions, thereby generating silver nanoshells on the surface of gold nanoparticles. The resulting nanoshells cause a significant plasmon color change, which can be clearly recognized by the naked eye in a wide range from $1.3 \times 10^{3}$ to $2.5 \times 10^{6}$ copies/ $\mu \mathrm{L}$ (56). Additionally, the immunocapture unit can capture different wanted targets (e.g., H7N9 virus and Zika virus) through conjugating suitable antibodies to achieve accurate and ultrasensitive detection. It can be anticipated that the proposed protocol could inspire and stimulate new developments in clinical diagnosis of SARS-CoV-2 viral protein with high accuracy and sensitivity by varying AIEgens with switchable luminescence. Compared to most turn-off fluorescent probes, the fluorescence turn-on property gives AIEgens a unique advantage in terms of signal reliability and sensitivity.

Lateral flow immunoassay is typically performed in a paperlike membrane strip with two lines (8). The test line is coated with colorimetric or fluorescent material-antibody conjugates, and the control line is coated with capture antibodies. After depositing the test person's blood on the membrane strip, the SARS-CoV-2 antibody (if present) can specifically bind to the colorimetric or fluorescent material-antibody conjugate while flowing through the test line. The resulting complex continues to move until it is immobilized by the capture antibodies on the control line, causing a visible line under daylight or ultraviolet (UV) light. It is worth noting that the sensitivity of the fluorescent signal is much higher than that of the colorimetric signal. By virtue of the AIE feature, AIEgens can be integrated into nanoparticles at high concentrations, resulting in one AIE dot for labeling in response to one binding unit (59-61). For example, AIEgenbased fluorescent microsphere (AIEFM) was obtained by selfassembly of poly(methyl methacrylate) (PMMA), poly (maleic anhydride-alt-1-octadecene) (PMAO), sodium dodecyl sulfate (SDS), and AIE-active TCBPE (Figures 2C,D). The hydrophilic part of PMAO acts outward as a functional group to conjugate with anti-E. coli O157:H7 monoclonal antibody, forming the fluorescent immunoprobe (AIEFM-mAb) (59). Anti-E. coli O157:H7 polyclonal antibody (pAb) was immobilized on the test line $(\mathrm{T})$ of the nitrocellulose membrane while goat antimouse antibody (sAb) was immobilized on the control line (C). The target E. coli O157:H7 (if present) can be specifically captured by mixing with AIEFM-mAb to generate bright fluorescence on both the test line and control line. Otherwise, AIEFM-mAb can only be captured by $\mathrm{sAb}$ on the control line to emit bright fluorescence. The advantage of using AIEactive TCBPE is that the higher the loading of TCBPE, the stronger the fluorescence signal and the higher the detection sensitivity. As a result, the AIEFM endows the lateral flow immunosensor with a very low detection limit, down to $3.98 \times$ $10^{3} \mathrm{CFU} / \mathrm{mL}$, which is about 10 times lower than that of the two commercial FMs (59). Undoubtedly, the above strategy is also applicable to the construction of lateral flow immunoassay kits for detecting SARS-CoV-2 antigen and antibody. Higher performance detection can be achieved not only by using different AIEgens for AIEFM, but also by using other AIE dots. In addition, some news reported that lateral flow immunoassay 


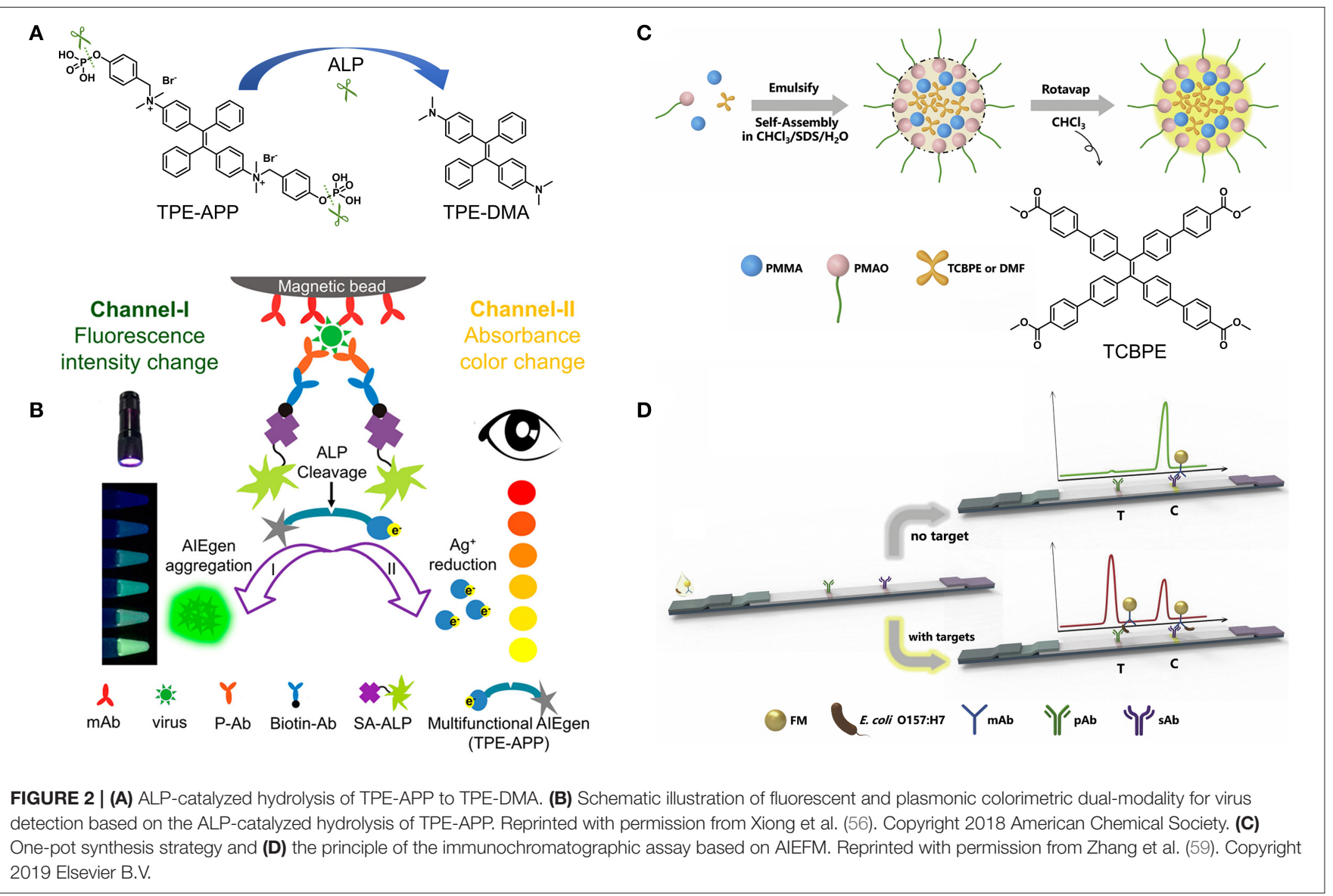

kits for SARS-CoV-2 antigen or antibody detection have been developed through the use of highly luminescent AIE dots (62, 63). Therefore, it is reasonable to conclude that AIEgens-/AIE dots-based SARS-CoV-2 immunoassay kits can be designed and produced with higher sensitivity and lower detection limit.

To facilitate the understanding and utilization of AIE dots, current AIE dots are divide into two categories: pure AIE dots and composite AIE dots (22-25). The commonly used preparation method is anti-solvent precipitation, which is achieved by adding an anti-solvent in which AIEgens are poorly soluble or by reducing the volume of a solvent in which AIEgens are well soluble. This method is convenient and principally applicable to any AIEgen to form the pure AIE dots. However, the formed pure AIE dots usually have difficult to control particle morphology (e.g., spheres, ellipsoids, and bulk amorphous), particle size, and surface modification, making them difficult to perform desired and specific applications. To overcome these difficulties, more sophisticated molecular designs and synthetic efforts are required to obtain functional AIEgens. On the other hand, the composite AIE dots are formed from encapsulating various AIEgens into the different amphiphile matrices. The amphiphile matrices provide not only stability for the AIE dots and water solubility for the organic AIEgens, but also enhance the control of morphology and size of AIE dots. By simultaneously precipitating AIEgens and amphiphilic matrices, spherical AIE dots of uniform particle sizes are usually produced, which can be easily further modified. The commercial matrices include, but are not limited to: poly(ethylene glycol) derivatives (e.g., 1,2-distearoyl-sn-glycero-3-phosphoethanolamine$\mathrm{N}$-[methoxy(polyethylene glycol)-2000] (DSPE-PEG 2000 ), poly(ethylene glycol)-b-polystyrene (PEG- $b$-PS), 1,2-distearoylsn-glycero-3-phosphoethanolamine- $\mathrm{N}$-[folate(polyethylene glycol)-5000] (DSPE-PEG 5000 -folate), etc.), bovine serum albumin (BSA), and biocompatible surfactants (e.g., pluronic F127 and lecithin). It is worth noting that the internal dispersion of AIEgens throughout the amphiphilic matrix may be stochastic and vary from molecular to aggregate distributions when preparing and using the composite AIE dots. Compared to the pure AIE dots, the composite AIE dots preserve the properties of both materials to offer a number of unique advantages: (1) synthetic efforts are minimized by reducing the hydrophilic groups; (2) luminescence performance are well-tuned by mixing various AIEgens in different concentrations; and (3) high specificity and responsiveness are achieved by using the amphiphilic matrices to conjugate with diverse linkers.

\section{CONCLUSION}

Global health is facing the most dangerous situation regarding the COVID-19 pandemic. Owing to the large number of infected cases worldwide, the rapid long-term spread, and lack of effective treatments, there is a continuing need for more sensitive, low-cost, rapid, and point-of-care diagnostic kits to 


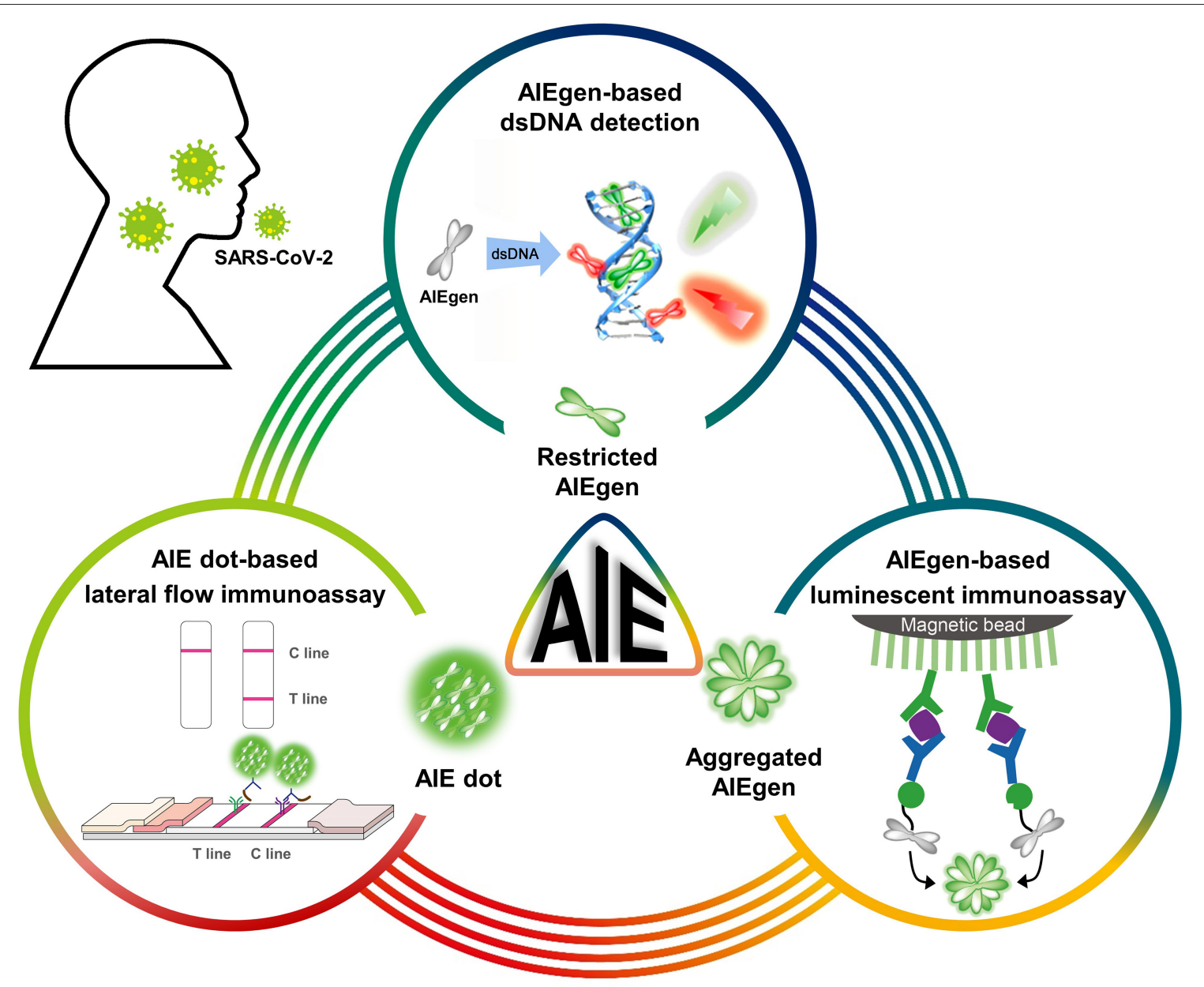

SCHEME 1 | Schematic diagram of AIEgens and AIE dots as potential tools for COVID-19 detection. Partially cited from Gao et al. (48), Xiong et al. (56), and Zhang et al. (59).

identify cases of SARS-CoV-2 infection in communities and individuals without advanced facilities. To date, while RTPCR assays have become the primary technique for detection of SARS-CoV-2 RNA, other nucleic acid assays including isothermal amplification assays, hybridization microarray assays, amplicon-based metagenomics sequencing, and the cutting-edge CRISPR-related technologies have also been developed (64). Challenges related to current nucleic acid assays mainly include improving detection sensitivity to eliminate false negatives and performing rapid and point-of-care tests outside of sophisticated laboratories. On the other hand, immunological assays are capable of detecting both SARS-CoV-2 antigens and antibodies. Immunoassays for antigens enable direct, rapid, low-cost, and point-of-care detection of SARS-CoV-2 infection at an early stage. Since antigen proteins are unable to be amplified like viral genes, it is crucial to develop new fluorescent probes to improve sensitivity. Immunoassays for antibodies can provide valuable knowledge about the course and extent of the immune response, which are useful in further identifying infected individuals and their close contacts. In particular, the immune persistence of healthy participants can be well-tracked during the vaccination phase. Based on the challenges present in these assays, this review highlights the inherent advantages of AIEgens and AIE dots that can help improve sensitivity (Scheme 1). AIEgens used in nucleic acid assays show negligible fluorescence in the free state but turnon fluorescence upon binding to dsDNA, and the fluorescence signals increase with the binding numbers without the ACQ problem. Similarly, the AIE dots used in the immunoassays can continuously increase the fluorescence intensity by increasing the loading concentration of AIEgens.

In addition, there are some issues that need further improvement when AIE materials are used to COVID-19 detection: (1) development of the sequence-specific DNA probes labeled with AIE dots and quenchers; (2) promotion of AIE dots-based lateral flow immunoassay kits for COVID-19 clinical testing; (3) diversification of AIEgens and AIE dots that can be directly labeled with highly targeted molecules (e.g., antibodies); and (4) further attempts to use AIE materials for studying immune mechanisms and pharmacological treatment of COVID-19 infection (65). With these solid 
foundations and promising possibilities, there is no doubt that AIE materials should be regarded as a promising anti-SARS-CoV-2 weapon.

\section{AUTHOR CONTRIBUTIONS}

All authors listed have made a substantial, direct and intellectual contribution to the work, and approved it for publication.

\section{REFERENCES}

1. World Health Organization. WHO Coronavirus Disease (COVID-19) Dashboard. (2020). Available online at: https://covid19.who.int (accessed January 5, 2021).

2. Kumari P, Singh A, Ngasainao MR, Shakeel I, Singh IK, MI H, et al. Potential diagnostics and therapeutic approaches in COVID-19. Clin Chim Acta. (2020) 510:488-97. doi: 10.1016/j.cca.2020.08.013

3. Carter-Timofte ME, Jorgensen SE, Freytag MR, Thomsen MM, Hait AS, Mogensen TH, et al. Deciphering the role of host genetics in susceptibility to severe COVID-19. Front Immunol. (2020) 11:1606. doi: 10.3389/fimmu.2020.01606

4. Wiersinga WJ, Rhodes A, Cheng AC, Peacock SJ, Prescott HC. Pathophysiology, transmission, diagnosis, and treatment of coronavirus disease 2019 (COVID-19). J Am Med Assoc. (2020) 324:782-93. doi: 10.1001/jama.2020.12839

5. Freeman TL, Swartz TH. Targeting the NLRP3 Inflammasome in Severe COVID-19. Front. Immunol. (2020) 11:1518. doi: 10.3389/fimmu.2020.01518

6. Li F, Li W, Farzan M, Harrison SC. Structure of SARS coronavirus spike receptor-binding domain complexed with receptor. Science. (2005) 309:18641868. doi: $10.1126 /$ science. 1116480

7. Aoshi T, Koyama S, Kobiyama K, Akira S, Ishii KJ. Innate and adaptive immune responses to viral infection and vaccination. Curr Opin Virol. (2011) 1:226-232. doi: 10.1016/j.coviro.2011.07.002

8. Carter LJ, Garner LV, Smoot JW, Li Y, Zhou Q, Saveson CJ, et al. Assay techniques and test development for COVID-19 diagnosis. ACS Cent Sci. (2020) 6:591-605. doi: 10.1021/acscentsci.0c00501

9. Esbin MN, Whitney ON, Chong S, Maurer A, Darzacq X, Tjian R. Overcoming the bottleneck to widespread testing: a rapid review of nucleic acid testing approaches for COVID-19 detection. RNA. (2020) 26:771-83. doi: 10.1261/rna.076232.120

10. Thompson D, Lei Y. Mini review: recent progress in RT-LAMP enabled COVID-19 detection. Sensors Actuat Rep. (2020) 2:100017. doi: 10.1016/j.snr.2020.100017

11. Jayamohan H, Lambert CJ, Sant HJ, Jafek A, Patel D, Feng H, et al. SARS-CoV-2 pandemic: a review of molecular diagnostic tools including sample collection and commercial response with associated advantages and limitations. Anal Bioanal Chem. (2021) 413:49-71. doi: 10.1007/s00216-020-02958-1

12. Sharifi M, Hasan A, Haghighat S, Taghizadeh A, Attar F, Bloukh SH, et al. Rapid diagnostics of coronavirus disease 2019 in early stages using nanobiosensors: challenges and opportunities. Talanta. (2021) 223:121704. doi: 10.1016/j.talanta.2020.121704

13. Tang YW, Schmitz JE, Persing DH, Stratton CW. Laboratory diagnosis of COVID-19: current issues and challenges. J Clin Microbiol. (2020) 58: e0051220. doi: 10.1128/JCM.00512-20

14. Luo J, Xie Z, Lam JWY, Cheng L, Chen H, Tang BZ, et al. Aggregationinduced emission of 1-methyl-1,2,3,4,5-pentaphenylsilole. Chem Commun. (2001) 18:1740-41. doi: 10.1039/b105159h

15. Mei J, Leung NLC, Kwok RTK, Lam JWY, Tang BZ. Aggregation-induced emission: together we shine, united we soar. Chem Rev. (2015) 115:11718-940. doi: 10.1021/acs.chemrev.5b00263

16. Zhao Z, Zhang H, Lam JWY, Tang BZ. Aggregation-induced emission: new vistas at the aggregate level. Angew Chem Int Ed. (2020) 59:9888-907. doi: 10.1002/anie.201916729

\section{FUNDING}

This work was supported by the National Natural Science Foundation of China (21804006 and 81903092), Beijing Natural Science Foundation (2212013), Science Foundation of Tianjin Health Bureau (RC20190), the Fundamental Research Funds for the Central Universities (buctrc201820), and Changjiang Scholars and Innovative Research Team (No. IRT_14R40).

17. Liu B, Zhang H, Liu S, Sun J, Zhang X, Tang BZ. Polymerization-induced emission. Mater Horiz. (2020) 7:987-98. doi: 10.1039/c9mh01909j

18. Suzuki S, Sasaki S, Sairi AS, Iwai R, Tang BZ, Konishi G. Principles of aggregation-induced emission: design of deactivation pathways for advanced AIEgens and applications. Angew Chem Int Ed. (2020) 59:9856-67. doi: 10.1002/anie.202000940

19. Li X, Li M, Yang M, Xiao H, Wang L, James TD, et al. “Irregular” aggregationinduced emission luminogens. Coord Chem Rev. (2020) 418:213358. doi: 10.1016/j.ccr.2020.213358

20. Wang Y, Nie J, Fang W, Yang L, Hu Q, Tang BZ, et al. Sugar-based aggregationinduced emission luminogens: design, structures, and applications. Chem Rev. (2020) 120:4534-77. doi: 10.1021/acs.chemrev.9b00814

21. Xu S, Duan Y, Liu B. Precise molecular design for high-performance luminogens with aggregation-induced emission. Adv Mater. (2020) 32:1903530. doi: 10.1002/adma.201903530

22. Li K, Liu B. Polymer-encapsulated organic nanoparticles for fluorescence and photoacoustic imaging. Chem Soc Rev. (2014) 43:6570-97. doi: $10.1039 / \mathrm{c} 4 \mathrm{cs} 00014 \mathrm{e}$

23. Chen S, Wang H, Hong Y, Tang BZ. Fabrication of fluorescent nanoparticles based on AIE luminogens (AIE dots) and their applications in bioimaging. Mater Horiz. (2016) 3:283-93. doi: 10.1039/c6mh00060f

24. Feng G, Liu B. Aggregation-induced emission (AIE) dots: emerging theranostic nanolights. Acc Chem Res. (2018) 51:1404-14. doi: 10.1021/acs.accounts.8b00060

25. Liu H, Xiong LH, Kwok RTK, He X, Lam JWY, Tang BZ. AIE bioconjugates for biomedical applications. Adv Optical Mater. (2020) 8:2000162. doi: 10.1002/adom.202000162

26. Wang D, Tang BZ. Aggregation-induced emission luminogens for activity-based sensing. Acc Chem Res. (2019) 52:2559-70. doi: 10.1021/acs.accounts.9b00305

27. Zhang $\mathrm{MM}, \mathrm{Li} \mathrm{K}$, Zang SQ. Progress in atomically precise coinage metal clusters with aggregation-induced emission and circularly polarized luminescence. Adv Optical Mater. (2020) 8:1902152. doi: 10.1002/adom.201902152

28. Cai X, Liu B. Aggregation-induced emission: recent advances in materials and biomedical applications. Angew Chem Int Ed. (2020) 59:9868-86. doi: 10.1002/anie.202000845

29. Song N, Zhang Z, Liu P, Yang YW, Wang D, Tang BZ, et al. Nanomaterials with supramolecular assembly based on AIE luminogens for theranostic applications. Adv Mater. (2020) 32:2004208. doi: 10.1002/adma.202004208

30. Jiang M, Gu X, Lam JWY, Zhang Y, Kwok RTK, Tang BZ, et al. Two-photon AIE bio-probe with large Stokes shift for specific imaging of lipid droplets. Chem Sci. (2017) 8:5440-6. doi: 10.1039/c7sc01400g

31. Yao W, Tebyetekerwa M, Bian X, Li W, Qin A, Tang BZ, et al. Materials interaction in aggregation-induced emission (AIE)-based fluorescent resin for smart coatings. J Mater Chem C. (2018) 6:12849-57. doi: 10.1039/c8tc04175j

32. Li W, Ding Y, Tebyetekerwa M, Xie Y, Qin A, Tang BZ, et al. Fluorescent aggregation-induced emission (AIE)-based thermosetting electrospun nanofibers: fabrication, properties and applications. Mater Chem Front. (2019) 3:2491-8. doi: 10.1039/c9qm00342h

33. Guan W, Yang T, Lu C. Measurement of solubilization location in micelles using anchored aggregation-induced emission donors. Angew Chem Int Ed. (2020) 59:12800-5. doi: 10.1002/anie.202005085

34. Tong $\mathrm{H}$, Hong $\mathrm{Y}$, Dong $\mathrm{Y}$, Haußler $\mathrm{M}$, Lam JWY, Tang BZ, et al. Fluorescent "light-up" bioprobes based on tetraphenylethylene derivatives 
with aggregation-induced emission characteristics. Chem Commun. (2006) 42:3705-7. doi: 10.1039/b608425g

35. Hong Y, Haußler M, Lam JWY, Li Z, Sin KK, Tang BZ, et al. Label-free fluorescent probing of G-quadruplex formation and real-time monitoring of DNA folding by a quaternized tetraphenylethene salt with aggregation-induced emission characteristics. Chem Eur J. (2008) 14:6428-37. doi: 10.1002/chem.200701723

36. Hong Y, Xiong H, Lam JWY, Hußler M, Liu J, Tang BZ, et al. Fluorescent bioprobes: structural matching in the docking processes of aggregationinduced emission fluorogens on DNA surfaces. Chem Eur J. (2010) 16:123245. doi: $10.1002 /$ chem. 200900778

37. Li S, Langenegger SM, Haner R. Control of aggregation-induced emission by DNA hybridization. Chem Commun. (2013) 49:5835-7. doi: $10.1039 / \mathrm{c} 3 \mathrm{cc} 42706 \mathrm{~d}$

38. Hong Y, Chen S, Leung CWT, Lam JWY, Tang BZ. Water-soluble tetraphenylethene derivatives as fluorescent "light-up" probes for nucleic acid detection and their applications in cell imaging. Chem Asian J. (2013) 8:1806-12. doi: 10.1002/asia.201300065

39. Xu L, Zhu Z, Wei D, Zhou X, Qin J, Yang C. Amino-modified tetraphenylethene derivatives as nucleic acid stain: relationship between the structure and sensitivity. ACS Appl Mater Interfaces. (2014) 6:18344-51. doi: 10.1021/am505791f

40. Xu X, Yan S, Zhou Y, Huang R, Chen Y, Zhou X, et al. A novel aggregationinduced emission fluorescent probe for nucleic acid detection and its applications in cell imaging. Bioorg Med Chem Lett. (2014) 24:1654-6. doi: 10.1016/j.bmcl.2014.02.071

41. Chen J, Wang Y, Li W, Zhou H, Li Y, Yu C. Nucleic acid-induced tetraphenylethene probe noncovalent self-assembly and the superquenching of aggregation-induced emission. Anal Chem. (2014) 86:9866-72. doi: 10.1021/ac502496h

42. Xu L, Zhu Z, Zhou X, Qin J, Yang C. A highly sensitive nucleic acid stain based on amino-modified tetraphenylethene: the influence of configuration. Chem Commun. (2014) 50:6494-7. doi: 10.1039/c4cc02671c

43. Zhao Y, Yu CYY, Kwok RTK, Chen S, Lam JWY, Tang BZ, et al. Photostable AIE fluorogens for accurate and sensitive detection of S-phase DNA synthesis and cell proliferation. J Mater Chem B. (2015) 3:4993-6. doi: $10.1039 / \mathrm{c} 5 \mathrm{tb} 00458 \mathrm{f}$

44. Wang $\mathrm{H}, \mathrm{Ma} \mathrm{K}, \mathrm{Xu} \mathrm{B}$, Tian $\mathrm{W}$. Tunable supramolecular interactions of aggregation-induced emission probe and graphene oxide with biomolecules: an approach toward ultrasensitive label-free and "turn-on" DNA sensing. Small. (2016) 12:6613-22. doi: 10.1002/smll.201601544

45. Tyagi A, Chu KL, Abidi IH, Cagang AA, Leung NLC, Tang BZ, et al. Single-probe multistate detection of DNA via aggregation-induced emission on a graphene oxide platform. Acta Biomater. (2017) 50:334-43. doi: 10.1016/j.actbio.2016.12.003

46. Ou X, Hong F, Zhang Z, Gao P, Lou X, Xia F, et al. A highly sensitive and facile graphene oxide-based nucleic acid probe: label-free detection of telomerase activity in cancer patient's urine using AIEgens. Biosens Bioelectron. (2017) 89:417-21. doi: 10.1016/j.bios.2016.05.035

47. Wang Z, Gu Y, Liu J, Cheng X, Sun JZ, Tang BZ, et al. A novel pyridinium modified tetraphenylethene: AIE-activity, mechanochromism, DNA detection and mitochondrial imaging. J Mater Chem B. (2018) 6:127985. doi: $10.1039 / \mathrm{c} 7 \mathrm{tb} 03012 \mathrm{f}$

48. Gao Y, He Z, He X, Zhang H, Weng J, Tang BZ, et al. Dual-color emissive AIEgen for specific and label-free double-stranded DNA recognition and single-nucleotide polymorphisms detection. J Am Chem Soc. (2019) 141:20097-106. doi: 10.1021/jacs.9b09239

49. Kotras C, Fossepre M, Roger M, Gervais V, Richeter S, Clementr S, et al. A cationic tetraphenylethene as a light-up supramolecular probe for DNA G-quadruplexes. Front Chem. (2019) 7:493. doi: 10.3389/fchem.2019. 00493

50. Liu H, Zhang Z, Zhao Y, Zhou Y, Zhou X, Li Z, et al. A water-soluble twodimensional supramolecular organic framework with aggregation-induced emission for DNA affinity and live-cell imaging. J Mater Chem B. (2019) 7:1435-41. doi: 10.1039/c8tb03206h

51. Shen J, Zhang Y, Hu R, Kwok RTK, Qin A, Tang BZ, et al. Dualmode ultrasensitive detection of nucleic acids via an aqueous "Seesaw" srategy by combining aggregation-induced emission and plasmonic colorimetry. ACS Appl Nano Mater. (2019) 2:163-9. doi: 10.1021/acsanm. $8 \mathrm{~b} 01773$

52. Yuan YX, Zhang HC, Hu M, Zhou Q, Wu BX, Zheng YS, et al. Enhanced DNA sensing and chiroptical performance by restriction of double-bond rotation of AIE cis-tetraphenylethylene macrocycle diammoniums. Org Lett. (2020) 22:1836-40. doi: 10.1021/acs.orglett.0c00174

53. Yu KK, Li K, He HZ, Liu YH, Bao JK, Yu XQ. A label-free fluorescent probe for accurate mitochondrial G-quadruplex structures tracking via assembly hindered rotation induced emission. Sens Actuators B. (2020) 321:128479. doi: 10.1016/j.snb.2020.128479

54. Wang X, Hu J, Zhang G, Liu S. Highly selective fluorogenic multianalyte biosensors constructed via enzyme-catalyzed coupling and aggregationinduced emission. J Am Chem Soc. (2014) 136:9890-3. doi: 10.1021/ja505278w

55. Engels JF, Roose J, Zhai DS, Yip KM, Tang BZ, Renneberg R, et al. Aggregation-induced emissive nanoparticles for fluorescence signaling in a low cost paper-based immunoassay. Colloids Surf B. (2016) 143:440-6. doi: 10.1016/j.colsurfb.2016.03.051

56. Xiong LH, He X, Zhao Z, Kwok RTK, Zhang R, Tang BZ, et al. Ultrasensitive virion immunoassay platform with dual-modality based on a multifunctional aggregation-induced emission luminogen. ACS Nano. (2018) 12:9549-57. doi: 10.1021/acsnano.8b05270

57. Yu W, Li Y, Xie B, Ma M, Tang BZ, Shen J, et al. An aggregation-induced emission-based indirect competitive immunoassay for fluorescence "turnon" detection of drug residues in foodstuffs. Front Chem. (2019) 7:228. doi: $10.3389 /$ fchem.2019.00228

58. Wu W, Shen M, Liu X, Shen L, Ke X, Li W. Highly sensitive fluorescencelinked immunosorbent assay based on aggregation-induced emission luminogens incorporated nanobeads. Biosens. Bioelectron. (2020) 150:111912. doi: 10.1016/j.bios.2019.111912

59. Zhang G, Xu S, Xiong Y, Duan H, Yuan M, Lai W, et al. Ultrabright fluorescent microsphere and its novel application for improving the sensitivity of immunochromatographic assay. Biosens Bioelectron. (2019) 135:173-80. doi: 10.1016/j.bios.2019.04.023

60. Wang Z, Hu S, Zhang G, Liu J, Peng J, Lai W, et al. Aggregationinduced emission-based competitive lateral flow immunoassay for rapid detection of sulfamethazine in honey. Food Agric Immunol. (2019) 30:1303-17. doi: 10.1080/09540105.2019. 1689929

61. Hu S, Liu J, Zhang G, Wang Z, Peng J, Lai W, et al. Reliable performance of aggregation-induced emission nanoparticle-based lateral flow assay for norfloxacin detection in nine types of animal-derived food. Talanta. (2020) 219:121245. doi: 10.1016/j.talanta.2020.121245

62. Office of Alumni Relations. Solutions for a Brighter, Post-pandemic Future. (2020). Available online at: http://www.nus.edu.sg/alumnet/thealumnus/ issue-122/perspectives/frontiers/solutions-for-a-brighter-post-pandemicfuture (accessed January 5, 2021).

63. The Hong Kong University of Science and Technology. What Do Tests for Fertility and COVID-19 Have in Common? (2020). Available online at: https://hkust.edu.hk/news/entrepreneurship/what-do-tests-fertility-andcovid-19-have-common? $\mathrm{cn}=1$ (accessed November 24, 2020).

64. Feng W, Newbigging AM, Le C, Zhang XE, Zhang H, Le XC, et al. Molecular diagnosis of COVID-19: challenges and research needs. Anal Chem. (2020) 92:10196-209. doi: 10.1021/acs.analchem.0c02060

65. Kang M, Zhang Z, Song N, Li M, Wang D, Tang BZ, et al. Aggregationenhanced theranostics: AIE sparkles in biomedical field. Aggregate. (2020) 1:80-106. doi: 10.1002/agt2.7

Conflict of Interest: The authors declare that the research was conducted in the absence of any commercial or financial relationships that could be construed as a potential conflict of interest.

Copyright (0) 2021 Liu, Meng, Tang, Tian and Guan. This is an open-access article distributed under the terms of the Creative Commons Attribution License (CC BY). The use, distribution or reproduction in other forums is permitted, provided the original author(s) and the copyright owner(s) are credited and that the original publication in this journal is cited, in accordance with accepted academic practice. No use, distribution or reproduction is permitted which does not comply with these terms. 